\title{
Introduction to the Special Issue: 'Introduction and intensification of agriculture in Central Eurasia and adjacent regions'
}

The Holocene

2016, Vol. 26(I0) 1523-1526

(C) The Author(s) 2016

Reprints and permissions:

sagepub.co.uk/journalsPermissions.nav DOI: I0.1 I77/09596836/6650270

hol.sagepub.com

\section{@SAGE}

\author{
Robert N Spengler III, 1,2,3 Pavel E Tarasov² and Mayke Wagner ${ }^{3}$
}

\begin{abstract}
For well over a century, scholars from across the social and biological sciences have been trying to understand the origins and spread of agriculture. This debate is often intertwined with discussions of climate change and human environmental impact. Over the past decade, this debate has spread into Central Eurasia, from western China to Ukraine and southern Russia to Turkmenistan, a part of the world often thought to have been largely dominated by pastoralists. A growing interest in the prehistory of Central Eurasia has spurred a new chapter in the origins of agriculture debate; archaeobotanical research is showing how important farming practices in this region were in regard to the spread of crops across the Old World. While early people living in Central Eurasia played an influential role in shaping human history, there is still limited understanding of the trajectories of social evolution among these populations. In March 2015, 30 leading scholars from around the globe came together in Berlin, Germany, to discuss the introduction and intensification of agriculture in Central Eurasia and adjacent regions. At the German Archaeological Institute in Berlin (Deutsches Archäologisches Institut, DAl), these scholars presented novel data on topics covering East, South, and Central Asia, spanning a wide realm of methodological approaches. The present special edition volume deals with a selection of the papers given at this conference, and it marks a significant step toward recognizing the contribution of Central Eurasian populations in the spread and development of agricultural systems over the course of the Holocene.
\end{abstract}

\section{Keywords}

archaeobotany, Central Eurasia, climate change, early agriculture, farming, human/environmental impact

Received 9 April 2016; revised manuscript accepted 10 April 2016

\section{Background}

The prehistoric people of Central Eurasia played a significant role in shaping history; they spawned innovations, such as advanced metallurgy and horse breeding, and spread ideas and technologies along the great Silk Road. However, the broad area of Central Eurasia, including the regions of Central Asia, Mongolia, and western China, has remained one of the largest gaps in our knowledge of the origins and spread of agriculture. Likewise, scholars have made great strides in understanding paleoclimate on a regional scale, but Central Eurasia has seen far fewer studies than other areas of Eurasia. Scholars who are involved in the originsof-agriculture debate often refer to this extensive geographic area as the 'Central Asian void'. The void spans over $5000 \mathrm{~km}$ from Ukraine to Mongolia and extends from Russia to Turkmenistan and covers a temporal span of at least 5000 years. Archaeologists working in Central Asia have formulated many of their research questions around a preconceived notion that the people living in this region had a pastoral-dominant economy, long referred to as the 'pastoral realm' or 'nomadic world', limiting the number of studies that have focused on early agriculture. However, in recent years, there has been a wave of new investigation into the origins and spread of agriculture across Central Eurasia; the present volume deals with this growing scholarly interest.

Few academics realize that one of the earliest archaeobotanical studies in the world was actually conducted in Central Asia. In
1904, Raphael Pumpelly led an expedition into the black sand dunes of the Kara Kum Desert, Turkmenistan, to study the remains of the ancient city of Anau. Pumpelly, an American geologist, and his close colleague Hubert Schmidt, a German archaeologist affiliated with Humboldt University in Berlin who also held a travel stipend from the Deutsches Archäologisches Institut (DAI) in the early 1890 s, had the foresight to employ faunal and floral experts to study the modern and ancient biota of Turkmenistan. The project botanist, Schellenberg, from Bern, Switzerland, conducted a detailed study of wheat and barley grain impressions from Anau, nearly half a century before macrobotanical methods were developed in Europe and America. Interestingly, Pumpelly focused many of his research questions around the origins of

IDepartment of Anthropology, Washington University in St. Louis, USA ${ }^{2}$ Section Palaeontology, Institute of Geological Sciences, Free University of Berlin, Germany

${ }^{3}$ Eurasia Department, German Archaeological Institute, Germany

\section{Corresponding author:}

Robert N Spengler III, Department of Anthropology, Washington University in St. Louis, CBI I I4, One Brookings Dr., St Louis, MO 63130, USA.

Email: junominerva@gmail.com 
agriculture debate. He also ran a multidisciplinary study, nearly half a century before similar studies would become commonplace, used dry sieving methods, systematic excavation, and detailed recording, a credit to his geology background, long before archaeologists would employ such methods.

Pumpelly was closely affiliated with the outspoken environmental determinist and geographer, Ellsworth Huntington (Harris and Coolidge, 2010: 44); building on, what were likely mutually developed ideas, Pumpelly became intrigued by the paleoclimate of Central Asia, and he envisioned climate change as a driving force for the origins and spread of agriculture. $\mathrm{He}$ studied the geology of paleochannels and dry lake beds across southern Central Asia, and ultimately hypothesized that the gradual desertification of southern Turkmenistan forced people into more restricted ecological pockets on an increasingly inhospitable landscape (Pumpelly, 1908: 65-66). He further theorized that as people were forced into these isolated loci, they had to adapt through agricultural innovation and ultimately irrigation - hence the origins of agriculture - foreshadowing the legendary 'Oasis Theory' of VG Childe (1928: 42, 1934: 24-25). Well over a century has passed since Pumpelly and Schmidt departed on their trek, and building on ideas that they first pioneered, several of the contributors to this volume have presented studies of the economy and environments of prehistoric Central Asia. As is evident in the pages that follow, the field has come a long way since that groundbreaking German/American expedition put their first shovel into the two tells of Anau.

During the early and mid-1990s, flotation techniques were introduced to Central Asia for the first time, rapidly changing the way scholars viewed the earliest economies in southern Central Asia. It became clear that the dawn of Central Asian civilization took place millennia before Anau was founded. In 1989, David Harris initiated excavations at the site of Jeitun; in 2010, he published a compilation of his career at the site, titled Origins of Agriculture in Western Central Asia. Harris' monograph has spurred a growing interest in the role Central Asian people played in the spread of agriculture and the development of productive economies. A handful of other pivotal investigations have been gradually building on the origins of agriculture debate in Central Asia. Naomi Miller started working in southern Central Asia in the 1990s, and she analyzed macrobotanical remains from Gonur Depe in Turkmenistan (Moore et al., 1994) and Jarkutan in Uzbekistan (Miller, 1999); George Willcox, working with French teams in 1990 and 1991, analyzed remains from Sarazm, Tajikistan (Spengler and Willcox, 2013), and Shortughai, Afghanistan. Claudia Chang and her colleagues started working in eastern Kazakhstan on the Talgar alluvial fan in 1994 (Chang et al., 2003; see also Spengler et al., 2013). As part of her multidisciplinary approach, she also brought Reinder Neef onto the Talgar team to conduct macrobotanical analyses in 1993, Miller in 1994, and Arlene Rosen, who conducted the first systematic phytolith research in Central Asia, during 1995 and 1997 (Rosen et al., 2000).

The rapidly growing number of archaeobotanical investigations published in recent years illustrates the new wave of scientific investigation sweeping across Central Eurasia. This research, which is ongoing, came to a culmination in Berlin, Germany, on 19-22 March 2015. Following in line with Pumpelly and Schmidt's collaborative German/American international project to study the ancient biota of Central Asia, the special edition volume presented here is the culmination of a German/American international project contributing to the same topic. The international collaboration between the organizers of this Special Issue of The Holocene was collectively sponsored by the Volkswagen, Mellon, and Wenner-Gren Foundations. These foundations also funded an international conference titled Introduction and Intensification of Agriculture in Central Eurasia. The conference was hosted by the DAI in Berlin. In all, 30 specialists, interested in early farming in Central Eurasia, originating from eight countries and over two dozen research institutes, came together in March 2015 , to discuss where the field has come since Schmidt departed from Berlin to excavate in Turkmenistan.

This conference was a jumping board for collaboration and put Central Eurasia on the map of agricultural spread - ultimately leading to this special edition. The debate over the origins and spread of agriculture in Central Eurasia is ongoing and intertwined with a global discussion of the development of human history world-wide. Inner Asia is an anomaly in discourse surrounding social complexity; the 1st millennium BC is marked by a demographic transition, social hierarchy, and craft specialization, long believed to be fueled by increased pastoralism. In the rest of the world, agriculture is accepted as a cornerstone to the development of social hierarchy and population growth. One of the least studied geographic areas, in terms of agricultural origins and spread, is also the region that breaks down the classical model of social development.

\section{Overviews of early agriculture in Central Eurasia}

The ultimate goal of the conference was to bring together an international group of scholars to discuss the growing realm of paleoeconomic and climatic data coming out of Central Eurasia; in many cases, these novel data do not fit the long-held models of economy in the region and demand that a new approach be taken. The volume consists of 15 contributions, opening with this introduction and four overview articles. The first of these overviews was composed by Spengler et al. and deals with the spread of agriculture into northern Central Asia. A series of recent publications have dealt with the topic of the spread of agriculture into the rest of Central Asia (see Spengler, 2015); however, the area of northern Central Asia is still relatively unexplored. Building on decades of research by Soviet and Russian scholars, Spengler et al. summarize the existing data for the spread of crops along the mountain chain of Central Asia into the Altai Mountains and eventually to Mongolia.

In a similar vein, Stevens et al. take a step back and look at large-scale social processes behind the spread of crops across Eurasia. They specifically focus on wheat, rice, broomcorn and foxtail millet, and peaches and apricots; they note that each of these important crops has a distinct narrative. Furthermore, they contrast and summarize the data supporting separate routes of crop dispersal through northern and southern Asia. Liu et al. also synthesize the data for the spread of southwest Asian cereals into the mountain foothills of Central Asia and eventually through the Hexi Corridor and into China. However, they go a step further and present a novel data set for the region. They apply Bayesian stable isotope mixing models to newly obtained isotopic data, with the ultimate goal of reconstructing the diet through a quantitative estimate of the contribution of different food resources.

Focusing specifically on the complex narrative behind the spread of broomcorn millet across the mountain foothill zone of Central Asia, Miller and her colleagues lay out the accepted model for the origins and spread of domesticated Panicum from East Asia to Eastern Europe. They also point out two interesting phases in the archaeobotanical remains for millet outside China. First, Miller et al. note that the early spread seems to be restricted to high rainfall areas, allowing low-investment farmers to cultivate a crop based on summer monsoonal rains. The second phase, starting around the 1st millennium BC, coincides with centralized irrigation projects across Eurasia, whereas millet became an important crop in multicropping systems, increasing productivity and stretching the farming season into the dry summer of more arid regions. 


\section{Paleoenvironments and paleoeconomy: Regional syntheses and case studies}

\section{East Asia}

The origins of agriculture in East Asia have been a heated topic of debate for decades; in recent years, the topics of the origins of domesticated rice (summarized in Stevens et al.) and broomcorn and foxtail millet (summarized in Miller et al.) have received a lot of attention from scholars. It is clear that rice was domesticated in the Lower Yangtze River valley; however, there is still a lack of comparative data from contemporaneous neighboring regions.

Hosner et al. explore the onset of sedentary agricultural communities in 25 provinces and autonomous regions of China, examining the distribution through time and space of archaeological sites. They consider in their study, over 51,000 archaeological sites from the early Neolithic to the early Iron Age, a period of 7.5 millennia. They argue for asynchronous patterns of change among populations in northern and southern parts of China; they track population increases and demographic patterns. Their analysis also shows a radical northeastern shift of high site density clusters from the Wei and middle/lower Yellow River valleys to the Liao River region sometime between 2350 and $1750 \mathrm{BC}$. This shift is further discussed in the context of the incorporation of West Asian domesticated animals and plants into the existing northern Chinese agricultural system.

Crawford et al. present archaeobotanical results from a study of c. 8000- to 7700-year-old sediment layers from the Houli Culture Yuezhuang site in Shandong Province, China. They argue that the economy of people at this settlement site was based on hunting and gathering of wetland plant and animal resources, and the low-investment management of animals as well as cultivation of millets and rice. Similarly, Jin et al. present a new archaeobotanical data set from the sites of Dongpan (4030-3820 BC) and Beiqian (3700-2900 BC) Shandong Province. While millet was clearly a significant component in the economy of people at Beiqian, the presence of rice, albeit in low abundance, at Dongpan is fascinating in regard to the study of the transition to farming. Building on their data and recently published archaeobotanical research, Jin et al. discuss new evidence for early rice exploitation from the regions located outside the core area of domestication in the lower Yangtze. These results partly fill an existing gap between the $c$. 8000-year-old rice remains from the early Neolithic Houli Culture (c. 6500-5500 BC) sites north of the Shandong Highlands and the late Neolithic Longshan Culture (c. 2600-1900 BC) sites with intensive rice agriculture. The archaeobotanical record suggests a major change in regional subsistence from strongly relying on wild resources and small-scale cultivation prior to $3800 \mathrm{BC}$ to a millet-based economy after that time.

$\mathrm{Ma}$ et al. also analyze a palynological core, providing a detailed study of climate change and human impact in East Asia, specifically over the last 8200 years. They present an analysis of a core from the Lantianyan peat bog in Zhejiang Province, China. Among other trends, they indicate a switch to rice paddy agriculture around $1600 \mathrm{BC}$.

Müller et al. present the results of a palynological analysis of sediment cores from Kushu Lake on Rebun Island in the Sea of Japan off the northwestern tip of Hokkaido, Japan. The article provides a chronology for human and climatic effects on the ecology of the Island over the past 17,000 years. They also identify the presence of barley in the economy, through macrobotanical remains, around AD 650-900, during the Okhotsk occupation phase.

Abe et al. also present results from the Hokkaido region of Japan, looking at the spatio-temporal distribution of hunter-gatherer archaeological sites from the Upper Paleolithic $(>12,000 \mathrm{BC})$ through the historic Ainu period (c. AD 1300-1900). Based on the settlement data, they argue for several environmentally driven shifts in economy, notably favoring hunting and gathering in the Middle Jomon period (c. 3000-2000 BC), which led to a growth in population size and density. The demographic shift, they hypothesize, led to a diversification and intensification in the breadth of food resources used. Eventually, a trend toward cooler climatic conditions corroborates a population decrease and changes in the diet.

\section{South Asia}

The broad geographic area of South Asia has a long history of productive economies, with agriculture in southwest Asia dating back to, at least, $8500 \mathrm{BC}$. The southwest Asian crops spread across the Old World and reached the eastern edge of the Iranian Plateau by 6000 BC. From there, they eventually spread into the Indus. Western India has been a mingling zone for domesticated crops for millennia as farmers experimented with plants from across South Asia and from as far away as North Africa. The story behind the spread and introduction of these crops is being pieced together, and it is laid out in part in the article by Stevens and his colleagues.

Demske et al. analyze a pollen core from a small lake, Badanital, in the upper catchment area of the Ganges, in northern India; they note both natural and human-induced patterns in the pollen assemblage. Interestingly, they argue that an abundance of Cannabis-type pollen confidently indicates local retting of hemp between $c .500 \mathrm{BC}$ to $\mathrm{AD} 1150$, although a process of small-scale use of hemp could have started about 500 years earlier.

Shumilovskikh et al. examine pollen, plant macrofossils, and several other bio- and geochemical proxies from a sediment core taken from Kongor Lake in the eastern Gorgan Plain (northeastern Iran). Based on these data, dating from a period stretching over the last $c$. 6000 years, they reconstruct paleoenvironment and agropastoral activities in the region. The strongest anthropogenic impact on the environment around the Kongor site is documented during the Parthian and Sasanian Empires (200 $\mathrm{BC}-\mathrm{AD}$ 651) and during the Islamic era up to the eve of the Mongol invasion.

\section{Northern Central Asia}

Central Asia has long been looked upon as the 'nomadic' world; however, archaeobotanical data clearly illustrate that agriculture spread into southern Central Asia, at Jeitun, by 6000 BC (Harris, 2010). After agriculture became well established in the Kopet Dag Mountains, it eventually spread to the northeast. The earliest evidence for domesticated crops north of the Pamir Mountains comes from the late 3rd millennium BC. As Spengler et al. demonstrate, agriculture eventually makes its way into the rest of the mountains of Central Asia by the late 2nd millennium BC. Broomcorn millet was among the early crops identified in eastern Kazakhstan, a crop that has received much attention from archaeologists and biologists in recent years. Miller et al. synthesize the data for the origins and spread of millet across Eurasian and then present a novel model in which climate and culture interact to explain the patterns of its spread.

The desiccated cemetery finds from Xinjiang in northwestern China have continued to amaze scholars and provide an astonishingly clear glimpse into the life and economy of people of Central Asia during the 1 st and 2nd millennia BC. Preserved foods and textiles continue to receive the spotlight, as they are exhumed from these tombs. Schröder et al. investigate artifacts from the desiccated burials of Xinjiang. They focus on leather goods from tombs in the graveyards of Wupu in the Hami Oasis and Yanghai in the Turpan Oasis of northwestern China. They extract DNA from the 1st millennium BC leather objects, arguing that leather was produced from domesticated sheep, goat, and cow.

Further to the north, less is generally known about changes in economy over time, including when pastoralism, based on sheep, 
goat, and cattle, as well as millet and cereal farming moved into the region. Spengler et al. analyze the spread of agriculture into northern Central Asia, but there is a dearth of data from the region of southwest Siberia and northern Kazakhstan. This is, specifically, the region where Motuzaite Matuzeviciute et al. studied changes in the economy of pastoralist populations during the 2 nd and 3rd millennia BC. They use $\delta^{13} \mathrm{C}$ or $\delta^{15} \mathrm{~N}$ values in bone collagen to illustrate a transition in the economy and discuss the key transition to sheep- and goat-based pastoralism in the southern zones of western Siberia (Upper Ob River) and northern Kazakhstan (Tobol River basin). Furthermore, they present stable isotope results of human and animal bone collagen from Neolithic populations in the region, allowing for a baseline of comparison.

The results of the conference and the articles in this volume clearly illustrate that Central Asia was more than just a pastoralist realm, agriculture was an important component in the paleoeconomy. While it is clear that the prehistory of Central Asia is more complicated than a simple pastoral versus farming dichotomy, some scholarship, specifically in northern Kazakhstan and in the southern parts of Siberia and the Ural Mountains, supports the idea that the economy in that area in the 2 nd millennium $\mathrm{BC}$ was pastoral-based and lacked agriculture. Work on the paleoeconomy of the Sintashta Culture by Stobbe et al. has not uncovered any evidence for domesticated grains in the diet, despite systematic flotation and detailed archaeobotanical studies. These findings are important, because they speak to the routes of spread and the role of various aspects of the productive economy across Eurasia in the past.

\section{Conclusion}

Well over a century after the Pumpelly and Schmidt expedition, and nearly a century after Childe and Vavilov first started their investigations, the scientific community has come a long way in the origins of agriculture debate. Most of the global map has been filled in for the timing and locations of both domestication and the spread of crops. In the October issues of Current Anthropology for 2009 and 2011, a compilation of articles was brought together as an attempt to synthesize the state of the field. Leading scholars from all realms of inquiry published the most recent results and most up-to-date data on when and how farming spread around the globe. Interestingly, the vast region of Central Eurasia, from Ukraine to Mongolia and south to Turkmenistan, was never mentioned in either of the two volumes. In an attempt to follow-up on this lacuna of data, the Wenner-Gren Foundation (the sponsor of the two aforementioned volumes and their accompanying conferences) sponsored our Berlin conference in 2015 on the origins of agriculture in Central Eurasia. The present special edition of The Holocene is the culmination of that conference, representing an attempt to put this part of the world on the map of agricultural spread.

\section{Acknowledgements}

The academic conference was held in Berlin, at the German Archaeological Institute (DAI) and co-hosted by the Institute and Free University (FU), Berlin. The conference was organized by Spengler, Wagner, and Tarasov and their staff members from the GAI and FU Berlin. The present volume is also a contribution to the 'Bridging Eurasia' research initiative of the Beijing Branch Office of the Eurasia Department, DAI (http://bridging-eurasia.org/ en), and the Institute of Geological Sciences of FU Berlin (http://
www.geo.fu-berlin.de/geol/fachrichtungen/pal/news/2014_Bridging-Eurasia.html). The research initiative informally unites an international and multidisciplinary team of scientists searching for high-resolution environmental and archaeological archives from Central and East Asia and aiming at correlating archaeological and environmental data at local to regional scale for finding the causality of changes (Wagner et al., 2014). M Wagner hosted and supported the conference in unison with $\mathrm{P}$ Tarasov.

\section{Funding}

Financial support for the conference came from a Wenner-Gren workshop grant (Gr. CONF-673) to aid 'Introduction and Intensification of Agriculture in Eurasia', as well as a workshop grant that was jointly funded by the Volkswagen and Mellon Foundations, attached to a larger Fellowship for Research in the Humanities for research in Germany, awarded to R Spengler.

\section{References}

Chang C, Benecke N, Grigoriev FP et al. (2003) Iron age society and chronology in South-East Kazakhstan. Antiquity 77: 298-312.

Childe VG (1928) The Most Ancient East: The Oriental Prelude to European Prehistory. London: Kegan, Paul, Trench, Trubner.

Childe VG (1934) New Light on the Most Ancient East. London: Routledge \& Kegan Paul.

Harris D (2010) Origins of Agriculture in Western Central Asia: An Environmental-Archaeological Study. Philadelphia, PA: University of Pennsylvania Museum of Archaeology and Anthropology.

Harris D and Coolidge J (2010) History of archaeological research. In: Harris DR (ed.) Origins of Agriculture in Western Central Asia: An Environmental-Archaeological Study. Philadelphia: University of Pennsylvania Museum of Archaeology and Anthropology, University of Pennsylvania Press, pp. $43-52$.

Miller NF (1999) Agricultural development in western Central Asia in the Chalcolithic and Bronze Ages. Vegetation History and Archaeobotany 8: 13-19.

Moore K, Miller NF, Heibert FT et al. (1994) Agriculture and herding in early oasis settlements of the Oxus Civilization. Antiquity 68: 418-427.

Pumpelly R (1908) Explorations in Turkestan, Expedition of 1904: Prehistoric Civilization of Anau (Book Two). Washington, DC: The Carnegie Institute of Washington.

Rosen AM, Chang C and Grigoriev FP (2000) Paleoenvironments and economy of Iron Age Saka-Wusun agro-pastoralists in southeastern Kazakhstan. Antiquity 74: 611-623.

Spengler RN III (2015) Agriculture in the Central Asian Bronze Age. Journal of World Prehistory 28: 215-253.

Spengler RN III and Willcox G (2013) Archaeobotanical results from Sarazm, Tajikistan, an Early Bronze Age village on the edge: Agriculture and exchange. Journal of Environmental Archaeology 18(3): 211-221.

Spengler RN III, Chang C and Tourtellotte PA (2013) Agricultural production in the Central Asian mountains, Tuzusai, Kazakhstan (410-150 BC). Journal of Field Archaeology 38(1): $68-85$.

Wagner M, Jin G and Tarasov PE (eds) (2014) The Bridging Eurasia research initiative: Modes of mobility and sustainability in the palaeoenvironmental and archaeological archives from Eurasia. Quaternary International 348: 1-266. 